\title{
Choledochal Cyst with Pancreatic Divisum- A Rare
}

\section{Occurrence}

\author{
Murali $\mathrm{K}^{1 *}$, Ashwin $\mathrm{G}^{2}$ and Anju $\mathrm{M}^{3}$ \\ ${ }^{1}$ Surgical Specialist, Military Hospital, India \\ ${ }^{2}$ Professor, Department of Surgery, Armed Forces Medical College, India \\ ${ }^{3}$ Resident, DNB Gastroenterology, Lakeshore Hospital and research Centre, India
}

\section{Case Report}

Volume 1 Issue 2

Received Date: September 11, 2017

Published Date: October 02, 2017

DOI: $10.23880 /$ mjccs- 16000112

*Corresponding author: Murali Krishna, Surgical Specialist, Military Hospital, Holta Camp, Palampur, Himachal Pradesh, India, Tel: 91-8411066008; E-mail: murali276@yahoo.com

\section{Abstract}

Though pancreatic divisum is the most common congenital anomaly of pancreas, its co-occurrence with choledochal cyst is a rare finding with less than ten reported cases in literature. Both these conditions are associated with significant morbidity to the patient. Also the understanding of patho-physiology of pancreatitis in pancreatic divisum is undergoing a change. In this case report, we discuss a case adult female who presented with chronic pain abdomen. The workup of the case, problems encountered and management is discussed.

Keywords: Choledochal cyst; Pancreatic divisum; Pancreatic calculi; Chronic pancreatitis; SPINK1 mutation

Abbreviations: MPD: Main Pancreatic Duct; CFTR: Cystic Fibrosis Transmembrane Conductance Regulator; PD: Pancreatic Divisum; APBJ: Abnormal Pancreatico Biliary Junction

\section{Introduction}

Pancreatic divisum (PD) is one of the most common congenital anomaly of pancreas [1] and is a known causative factor for chronic pancreatitis. The prevalence of PD based on autopsy and MRCP studies are around 8\% and based on ERCP studies vary from $4 \%$ to $8 \%$ [2]. Choledochal cyst is an abnormal dilatation of part of biliary tree. The incidence is comparatively high in Asian population (1 in 1000) with majority of the cases being reported from Japan [3]. An association of pancreatic divisum with choledochal cyst is not often seen. There are few case reports in literature with similar findings. The management option becomes limited in such cases as both pathology needs to be addressed. An associated large pancreatic duct calculi further narrows the management options. Here we present a case of Chronic Atrophic pancreatitis secondary to pancreatic divisum associated with multiple main pancreatic duct MPD calculi and choledochal cyst.

\section{Clinical Presentation}

31 year old female, presented with complaints of intermittent pain abdomen and vomiting. Pain was moderate to severe in intensity, located in epigastric region not radiating and had no aggravating or relieving factors. Patient had no history of jaundice or fever. On examination abdomen was essentially within normal limit except for tenderness in epigastric region on deep palpation.

On investigation her S. Bilirubin was $0.8 \mathrm{mg} / \mathrm{dl}$, AST $144 \mathrm{IU} / \mathrm{L}, \mathrm{ALT}-202 \mathrm{IU} / \mathrm{L}$. Serum lipase was $31 \mathrm{IU} / \mathrm{L}$ and ALP was $228 \mathrm{IU} / \mathrm{L}$. Patient underwent USG abdomen which showed dilated CBD with diameter of $22 \mathrm{~mm}$ at 


\section{Medical Journal of Clinical Trials \& Case Studies}

porta, atrophied pancreas with dilated main pancreatic duct and multiple calculi inside MPD. Patient underwent

further investigations in form of MRCP (Figure 1) and CECT abdomen the images of which are shown below.

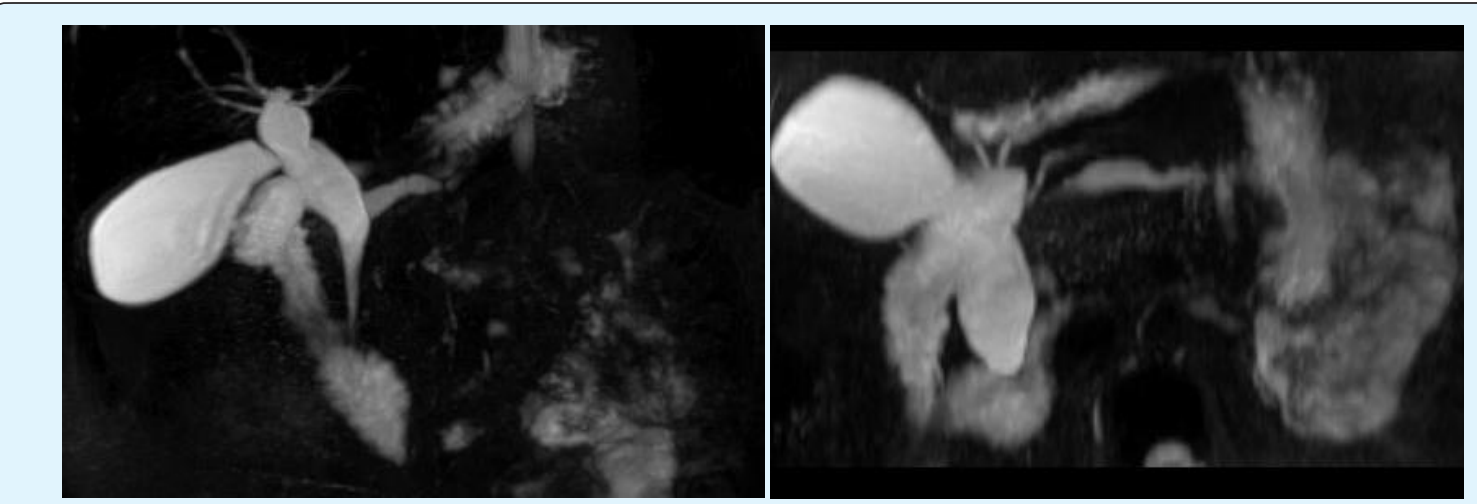

Figure 1: MRCP images showing dilated common duct and abnormal insertion of pancreatic duct.

The diagnosis of Choledochal cyst (Type 1) with pancreatic divsum (Type 1) was made after the investigations. The CT scan also showed multiple calculi in the MPD with largest calculi measuring $30 \mathrm{~mm}$ (Figure $2)$. Due to the multiple large calculi and presence of choledochal cyst an open surgery was planned. Intraop the findings of pancreatic divisum and choledochal cyst was confirmed. A Frey's procedure was done and calculi removed from MPD. Also the choledochal cyst was excised just below the confluence of hepatic ducts. Roux en Y pancreaticojejunostomy and hepatico-jejunostomy was done.

Patient remained stable in post op period and was discharged on post op day 8. Patient has remained on routine follow up and is presently asymptomatic.

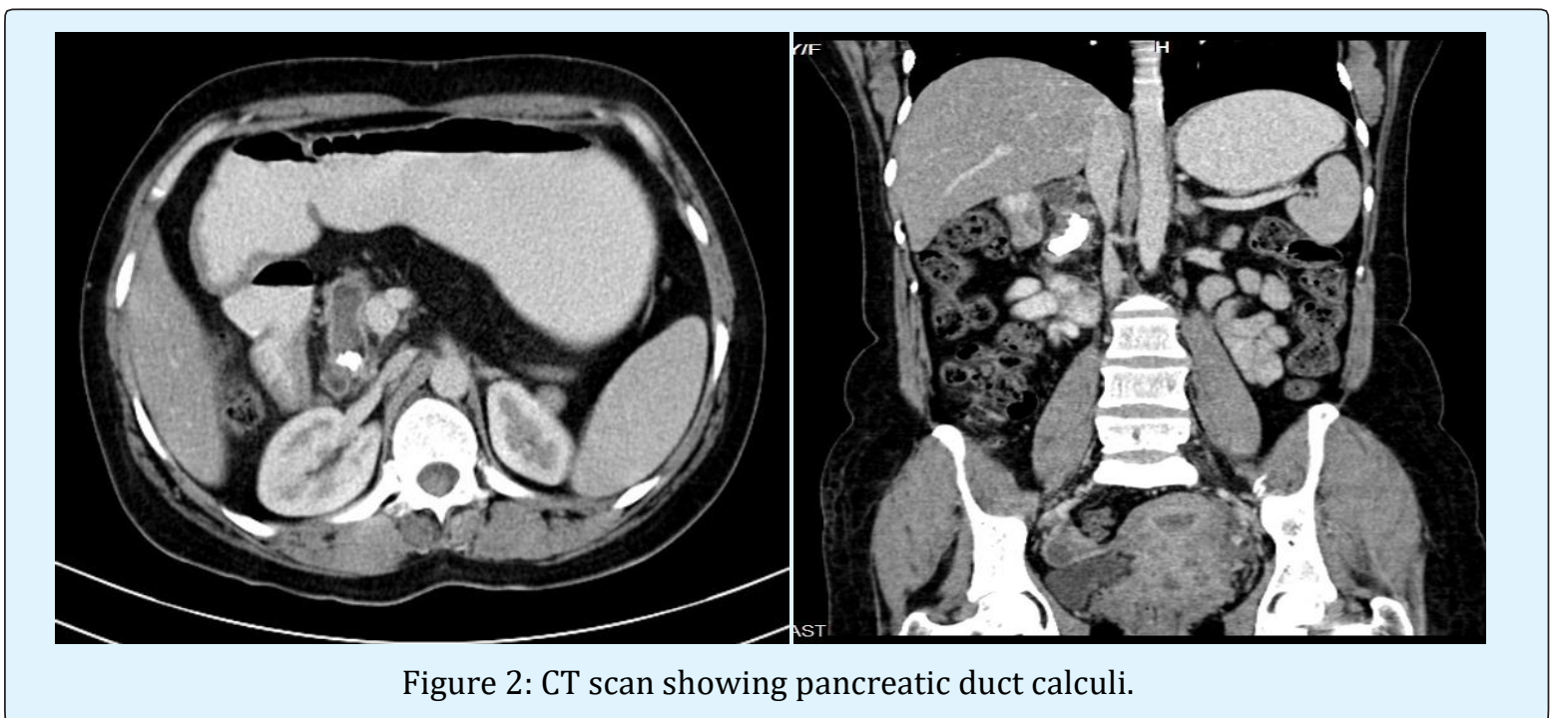

\section{Discussion}

Choledochal cyst in association with pancreatic divisum is a rare occurrence in adults. There are less than 10 cases reported till now in literature [4]. Both these condition on its own is associated with significant morbidity. While choledochal cyst is associated with cholangitis and biliary tract malignancy, PD is associated with recurrent acute pancreatitis (RAP) and chronic pancreatitis.
Pancreatic divisum (PD) is the most common congenital anomaly seen with pancreas. It occurs due to failure of fusion of dorsal and ventral pancreatic duct which usually occur at the end of second month of embryogenesis. Based on the degree of fusion of the duct PD is classified as Type 1, 2 and 3 as proposed by Warshaw, et al. [5].

Type 1: No communication between two ducts (70\%)

Type 2: Absent ventral duct (20-25\%)

Type 3: Incomplete/Partial/functional PD (5-6\%) 


\section{Medical Journal of Clinical Trials \& Case Studies}

The patho-physiological mechanism of RAP in patients of PD is a debatable topic. Why $90 \%$ of patients remain asymptomatic and a relative few presents with troublesome symptoms again remain a mystery. There have been reports of isolated dorsal pancreatitis associated with PD [6,7]. This is supposedly caused due to raised intraductal pressure following relative blockage of pancreatic secretion through minor papilla. However, reports of chronic pancreatitis involving both dorsal and ventral pancreas in patients of PD brings the above statement to question. Could there be a confounding factor in the hypothesis of causation of RAP?

The latest hypothesis suggests that PD is a supporting factor for genetic mutation leading to RAP. Studies show that the prevalence of PD is around $47 \%$ in patient of CFTR related pancreatitis and only $5 \%$ in idiopathic pancreatitis without genetic mutation [8]. Treatment of PD is indicated only in symptomatic patients and endoscopic therapy is the treatment of choice. The response rate of patients is variable. Patients of RAP had response ranging from 43 to $100 \%$ while in patients of chronic panceatitis, response ranged from 21 to $80 \%$ [9].

Choledochal cyst is classified by Todani, et al. [10] from Type I to type V. Type I which is usually a fusiform dilatation is the most common variant [10]. The pathogenesis of choledochal cyst is unclear. The 'common channel' theory as proposed by Babit, et al. still remains widely accepted. According to this theory, there is a reflux of pancreatic secretion into bile duct caused due to abnormal pancreatico biliary junction (APBJ). Other theories include those proposed by Singham, et al. \& Davenport, et al. [11,12]. Singham, et al. [11] proposed that the dilatation is caused due to embryological proliferation of epithelial cells. Davenport and Basu proposed that dilatation is due to decreased number of ganglion which causes distal obstruction and resultant proximal dilatation.

An article by ES Rho, et al. [13] describes a case of Choledochal type IV cyst with APBJ and associated SPINK1 gene mutation [13]. Whether SPINK1 mutation really has any role in pathogenesis of choledochal cyst remains to be found out. In a hypothetical sense, the activated pancreatic enzyme caused by SPINK1 mutation could cause weakening of bile duct wall.

The investigation of choice for diagnosis of choledochal cyst is MRCP and management involves surgical excision. The procedure followed depends on the type of cyst, but broadly involves complete excision of cyst and bilioenteric anastamosis to maintain continuity. Even after excision there is an increased risk of malignancy and hence patient should be kept on follow up.

\section{Conclusion}

Choledochal cyst with pancreatic divisum is not a common occurrence. The management options need to be considered on case to case basis. Evidence of genetic mutation playing role in patho-physiology of pancreatitis in pancreatic divisum is accumulating. If the same genetic mutation has any role in pathogenesis of choledochal cyst remains to be found out. Further studies on the prevalence of SPINK gene mutation in patients of choledochal cyst will help in solving this problem.

\section{References}

1. Mulholland MW, Moosa AR, Liddle RA (1995) Pancreas: anatomy and structural anomalies. Yamada T(Eds.). Textbook of Gastroenterology. Philadelphia, Pa: JB Lippincott.

2. Di Magno MJ, Wamsteker EJ (2011) Pancreas Divisum. Curr Gastroenterol Rep 13(2): 150-156.

3. Gigot J, Nagorney D, Farnell M, Moir C, Ilstrup D (1996) Bile duct cysts: A changing spectrum of disease. J Hepatobiliary Pancreat Surg 3(4): 405-411.

4. Ransom-Rodríguez ACA, Blachman-Braun R, Ramos ES G, Varela-Prieto J, Rosas Lezama E, et al. (2017) A rare case of choledochal cyst with pancreas divisum: case presentation and literature review. Ann HepatoBiliary Pancreat Surg 21(1): 52-56.

5. Warshaw AL, Simeone JF, Schapiro RH, FlavinWarshaw B (1990) Evaluation and treatment of dominant dorsal duct syndrome (pancreas divisum redefined). Am J Surg 159(1): 59-64.

6. Fogel EL, Toth TG, Lehman GA, DiMagno MJ, Di Magno EP (2007) Does endoscopic therapy favorably affect the outcome of patients who have recurrent acute pancreatitis and pancreas divisum? Pancreas 34(1): 21-45.

7. Spicak J, Poulova P, Plucnarova J, Rehor M, Filipova H, et al. (2007) Pancreas divisum does not modify the natural course of chronic pancreatitis. J Gastroenterol 42(2): 135-139.

8. Bertin C, Pelletier AL, Vullierme MP, Bienvenu T, Rebours V, et al. (2011) Pancreas divisum is not a cause of pancreatitis by itself but acts as a partner of genetic mutations. Am J Gastroenterol 107(2): 311317. 


\section{Medical Journal of Clinical Trials \& Case Studies}

9. Kanth R, Samji NS, Inaganti A, Komanapalli SD, Rivera $\mathrm{R}$, et al. (2014) Endotherapy in symptomatic pancreas divisum: A systematic review. Pancreatology 14(4): 244-250.

10. Todani T, Watanabe $Y$, Narusue $M$, Tabuchi $K$, Okajima K (1977) Congenital bile duct cysts: classification, operative procedures, and review of thirty-seven cases including cancer arising from choledochal cyst. Am J Surg 134(2): 263-269.

11. Singham J, Yoshida EM, Scudamore CH (2009) Choledochal cysts: part 1 of 3: classification and pathogenesis. Can J Surg 52(5): 434-440.
12. Davenport M, Basu R (2005) Under pressure: choledochal malformation manometry. J Pediat Sur 40(2): 331-335.

13. Rho ES, Kim E, Koh H, Yoo H-W, Lee BH, et al. (2013) Two cases of chronic pancreatitis associated with anomalous pancreaticobiliary ductal union andSPINK1mutation. Korean Journal of Pediatrics 56(5): 227-230. 